DOI: http://dx.doi.org/10.19177/reen.v9e12016204-231

http://portaldeperiodicos.unisul.br/index.php/EeN/index

\title{
O BALANCED SCORECARD EM ORGANIZAÇÕES SEM FINS ECONÔMICOS: UM ESTUDO DE CASO
}

THE BALANCED SCORECARD IN NON-ECONOMIC ORGANIZATIONS: A CASE STUDY

BALANCED SCORECARD EN ORGANIZACIONES NO ECONÓMICOS: UN ESTUDIO DE CASO

\section{Marcelo Medeiros da Rosa}

Mestrando em Contabilidade pela Universidade Federal de Santa Catarina

Endereço: R. Eng. Agronômico Andrei Cristian Ferreira, s/n, Trindade, CEP: 88040-900.

Florianópolis, SC, Brasil

Telefone: (48) 3721-9000

E-mail:mmr2801@yahoo.com.br

\section{Sérgio Murilo Petri}

Doutor em Engenharia de Produção pela Universidade Federal de Santa Catarina

Professor do Programa de Pós-Graduação em Contabilidade/Universidade Federal de Santa

Catarina

Endereço: R. Eng. Agronômico Andrei Cristian Ferreira, s/n, Trindade, CEP: 88040-900.

Florianópolis, SC, Brasil

Telefone: (48) 3721-9000

E-mail:smpetri@gmail.com

\section{Patrícia Bianco}

Graduanda em Ciências Contábeis pela Universidade Federal de Santa Catarina

Endereço: R. Eng. Agronômico Andrei Cristian Ferreira, s/n, Trindade, CEP: 88040-900.

Florianópolis, SC, Brasil

Telefone: (48) 3721-9000

E-mail: biancopa@yahoo.com.br

\section{Ibsem Agrello Dias}

Mestre em Administração pela Universidade do Sul de Santa Catarina (UNISUL)

Endereço: Praça Quinze de Novembro, Centro, CEP: 88010400. Florianópolis, SC, Brasil

Telefone: (48) 3239-3052

E-mail: ibsem.dias@gmail.com

Artigo recebido em 14/03/2015. Revisado por pares em 19/04/2016. Reformulado em 19/04/2016. Recomendado para publicação em 23/02/2016, por Ademar Dutra (Editor Científico). Publicado em 30/04/2015. Avaliado pelo Sistema doubleblindreview. 


\section{RESUMO}

Este artigo objetiva evidenciar a aplicabilidade do Balanced Scorecard (BSC) em organizações sem fins econômicos por meio da apresentação de uma pesquisa desenvolvida em uma fundação educacional. Metodologicamente, este artigo é classificado como descritivo e exploratório, com abordagem qualitativa, sob a forma de um estudo de caso. Como resultado, percebe-se que o BSC pode ser utilizado como uma ferramenta de gestão para entidades sem fins econômicos, uma vez que as interações causa-efeito demonstradas por meio dos painéis e do mapa estratégico da organização estudada contribuíram para a tradução da estratégia em metas mensuráveis e a ligação lógica entre os objetivos, os indicadores de desempenho e os resultados esperados, facilitando a compreensão, o controle e a execução das metas traçadas.

Palavras-chave: Balanced Scorecard; Avaliação de Desempenho; Gestão; Mapa Estratégico; Painel Estratégico.

\section{ABSTRACT}

This article aims to show the applicability of the Balanced Scorecard (BSC) in organizations without economic purposes through the presentation of a research developed in an educational foundation. Methodologically this article is classified as descriptive and exploratory with a qualitative approach, in the form of a case study. As a result, it is clear that the BSC can be used as a management tool for non-profit entities, since the interactions cause-effect demonstrated by means of panels and the strategic map of the organization studied contributed to the translation of strategy measurable targets and logical connection between objectives, performance indicators and the expected results, facilitating the understanding, control and enforcement of established targets.

Keywords: Balanced Scorecard; Performance Evaluation; Management; Strategic Map; Strategic Panel.

\section{RESUMEN}

Este artículo tiene el objetivo de evidenciar la aplicabilidad del Balanced Scorecard (BSC) en organizaciones no económicas por medio de la presentación de una investigación desarrollada en una fundación educacional. Metodológicamente, este artículo es clasificado como descriptivo y exploratorio, con abordaje cualitativo, bajo la forma de un estudio de caso. Como resultado se percebe que el BSC puede ser utilizado como una herramienta de gestión para entidades no económicas, pues que las interacciones causa-efecto demostradas por medio de paneles y del mapa estratégico de la organización estudiada contribuyeron para la traducción de la estrategia en metas mensurables y la ligación lógica entre los objetivos, los indicadores de desempeño y los resultados esperados, facilitando la comprensión, el control y la ejecución de las metas trazadas.

Palabras-clave: Balanced Scorecard; Avaliación de Desempeño; Gestión; Mapa Estratégico; Panel Estratégico. 


\section{INTRODUÇÃO}

De acordo com Machado et al. (2013), as frequentes mudanças no ambiente organizacional, em virtude da globalização e do aumento da competitividade, tornam as tarefas cada vez mais complexas e oportunizam novos arranjos institucionais. Soma-se a isso a deficiência do Estado na promoção de serviços públicos e o novo papel exercido pela sociedade - corresponsável pelas demandas sociais - como fatores que contribuíram para o crescimento de organizações sem fins econômicos no Brasil.

Até o final da década de 1980, o trabalho dessas organizações consistia em ações isoladas, de caráter assistencialista e sem grandes pretensões, que foram ganhando relevância pela formalização e pelo reconhecimento que seus atos impactam diretamente em aspectos sociais, culturais, econômicos e políticos na sociedade (LEBARCKY et al., 2009).

Para Lebarcky et al. (2009, p. 02), graças às origens e objetivos, muitas vezes associadas a iniciativas de autogestão e a movimentos voltados a questões sociais, "essas organizações desenvolveram resistência à adoção de práticas de gestão, vistas como ferramentas serviço do setor privado".

Neste sentido, Machado et al. (2013) afirmam que as entidades sem fins econômicos, embora tenham objetivos distintos das organizações empresariais, também fazem parte do novo ambiente de negócios, marcado pela competição e necessidade de informação. Essas organizações, segundos os autores, mesmo não tendo fins lucrativos, necessitam de viabilidade financeira para que possam cumprir a missão para a qual foram criadas.

Graças à relevância das organizações sem fins econômicos, entende-se que a discussão sobre a avaliação do desempenho destas entidades necessita de estudos mais aprofundados, uma vez que são escassos, quando comparados ao setor privado. Questões como construção de indicadores de desempenho e avaliação da gestão, presentes na realidade das empresas que visam ao lucro, deixam de ser o foco em organizações não governamentais e públicas. 
Com base no exposto, tem-se como problema de pesquisa: Como melhorar a gestão dessas entidades e proporcionar instrumentos para mensuração do desempenho de seus programas?

Para responder a pergunta de pesquisa, este artigo objetiva evidenciar a aplicabilidade do Balanced Scorecard em organizações sem fins econômicos, por meio da apresentação do resultado do processo de implantação do BSC - os indicadores de desempenho, a construção dos Painéis Estratégicos e de Indicadores e do Mapa Estratégico em uma fundação educacional sem fins econômicos presente em mais de 100 países, que possui um braço em Santa Catarina. Assim, espera-se analisar a efetividade do BSC como ferramenta de gestão e de mensuração de desempenho para a organização estudada.

O Balanced Scorecard (BSC) é um método de planejamento e avaliação flexível que permite a mensuração de resultados não apenas financeiros, mas sob a visão integrada da estratégia, da missão, de aspectos relacionados com clientes, com processos internos e com o aprendizado e crescimento organizacional. Por traduzir a missão e a estratégia em conjunto abrangente de medidas de desempenho, o BSC pode ser adaptado a qualquer tipo de organização, projeto ou programa (MOREIRA et al., 2012; NIVEN, 2007).

A justificativa desta pesquisa evidencia-se pela originalidade, importância e viabilidade (CASTRO, 1977). É original por não terem sido encontradas, na literatura consultada utilizando como fonte a base de dados dos periódicos da CAPES e anais de eventos (SEGeT e ENENGEP), publicações que discutam a aplicação do BSC em organizações sem fins econômicos, em especial, as educacionais. Esta pesquisa é importante por possibilitar, com base na análise dos dados, a avaliação do processo de implementação do BSC na entidade estudada, além de auxiliar futuros pesquisadores interessados no tema. É viável pela aplicabilidade de seus resultados e pela disponibilidade dos pesquisadores nas fases de coleta, sistematização e análise dos dados.

Este trabalho está estruturado em seções, sendo esta primeira de caráter introdutório acerca do tema de pesquisa e os objetivos do trabalho. A segunda apresenta o referencial teórico. Na terceira está a metodologia de pesquisa empregada em termos do enquadramento e do instrumento de pesquisa utilizado. A quarta apresenta a organização e o processo implantação do Balanced Scorecard - Mapa e Painéis Estratégicos. Na quinta e Revista Eletrônica de Estratégia \& Negócios, Florianópolis, v.9, n.1, jan./abr. 2016. 
última seção, evidencia-se como a pergunta de pesquisa e o objetivo foram alcançados, além da explanação dos resultados e das recomendações para trabalhos futuros.

\section{BALANCED SCORECARD (BSC)}

As mudanças ocorridas a partir do início do século XX nos contexto econômico, tecnológico e social afetaram, também, a forma de avaliar o desempenho das empresas. Lebarcky et al. (2009) afirmam que o único aspecto analisado até então era o financeiro, com base no retorno proporcionado aos seus sócios. A partir de 1950, outros critérios de avaliação de desempenho ganharam importância, como os que envolvessem aspectos relacionados aos clientes, à sociedade, aos funcionários, à estrutura e tecnologia, proporcionando a criação de modelos avaliativos que abrangessem estes aspectos.

Epstein (1997) e Atkinson e Epstein (2000) corroboram com esse entendimento, afirmando que a construção de metodologias de gestão ganhou pujança depois da II Guerra Mundial, onde foram desenvolvidos ferramentas de mensuração desempenho - nos Estados Unidos, criou-se um método semelhante ao BSC na Ford e na General Eletric. Na Europa, empresas francesas desenvolveram o Tableau de Bord.

De acordo com Quintairos et al. (2009), o Balanced Scorecard (BSC) surgiu de um estudo intitulado Measuring Performance in the Organization of the Future, que tinha como finalidade desenvolver um novo modelo de medição de desempenho de empresas.

No primeiro momento, o escopo do BSC era a mensuração do desempenho organizacional. No entanto, após os primeiros testes em empresas voluntárias, Kaplan e Norton perceberam que a metodologia contribui para a implementação das estratégias traçadas para a mobilização de toda a organização no cumprimento dos objetivos estratégicos, para mensuração dos resultados de sua aplicação (DIAS; LIMA, ROSA, 2014; BIAZZO; GARENGO, 2012).

De acordo com Lima, Soares e Lima (2011), a nova realidade competitiva empresarial exigiu novas configurações nos sistemas de gestão e de mensuração, obrigando os executivos a repensarem seus métodos de avaliar seus processos e resultados, cada vez por meio de fatores não financeiros. 
O BSC permite avaliar o desempenho em dimensões financeiras e não financeiras como "um complemento à medida financeira, suprindo sua deficiência em monitorar os ativos intangíveis essenciais para o crescimento futuro" (KAPLAN; NORTON, 1997, p. 68).

A figura 1 apresenta a evolução da abordagem criada por Kaplan e Norton (2004):

Figura 1 - Evolução da abordagem do Balanced Scorecard

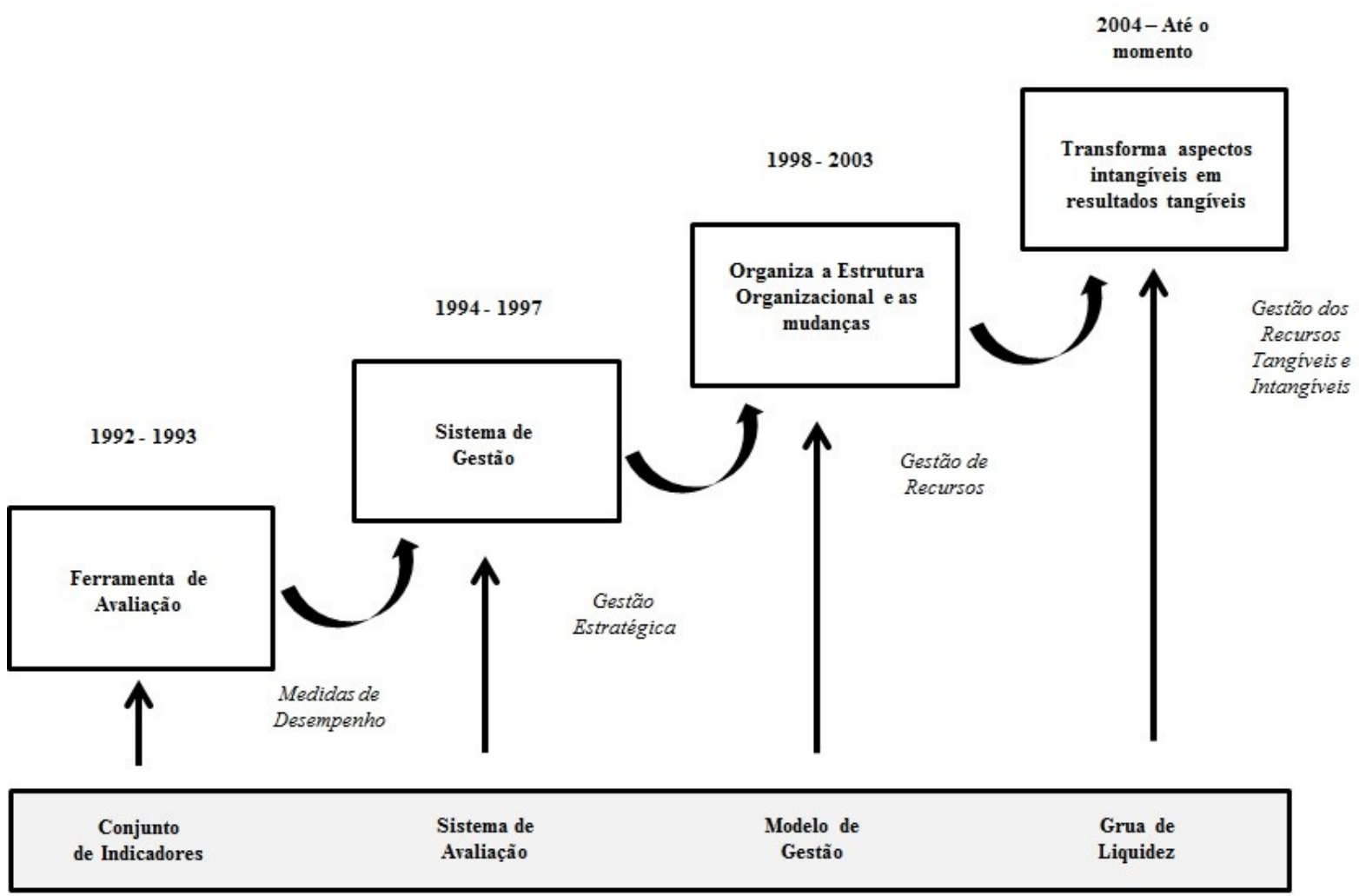

Fonte: Adaptado de Kaplan e Norton (2004) e Petri (2005).

O BSC, de acordo com Atkinson e Epstein (2000), representa a primeira tentativa de desenvolver um método de avaliação de desempenho com foco nos objetivos da empresa, na coordenação do processo de tomada de decisão e que proporcionasse o aprendizado organizacional. Ainda segundo os autores, esta ferramenta introduz um novo método de gestão que posiciona a estratégia como o cerne organizacional, tirando as questões financeiras do topo da hierarquia e colocando-as em pé de igualdade com outras questões pertinentes ao negócio - como a gestão dos processos e o relacionamento da empresa com seus clientes.

No primeiro momento, a ferramenta tinha como foco exclusivo a mensuração do 
desempenho organizacional (KAPLAN; NORTON, 1992). Entretanto, após os primeiros testes práticos em empresas voluntárias, percebeu-se que o BSC é um sistema de gestão que contribui para a implementação das estratégias e na mobilização de toda a organização para o cumprimento dos objetivos estratégicos, tanto na esfera privada quanto na pública - esta última requer adaptações devido a sua finalidade.

Para Kaplan e Norton (2000), entre as contribuições do Balanced Scorecard estão a visualização das medidas que reflitam a estratégia organizacional e a criação de uma rede de indicadores que englobe todos os níveis organizacionais, tornando-se, desta forma, uma ferramenta de comunicação e de promoção do comprometimento de todos os stakeholders com os objetivos da entidade.

De acordo com Petri (2005), o BSC permite que uma organização obtenha uma avaliação mais ampla de suas decisões estratégicas, e isto ocorre por meio de perspectivas. Outro aspecto relevante sobre a ferramenta é que o BSC tende a substituir o orçamento como o centro nervoso das organizações, graças a sua capacidade de integrar as variáveis que geram valor ao longo do tempo, e pela análise com base em diferentes e abrangentes (porém concisas) perspectivas. Tais perspectivas são: financeira, do cliente, dos processos internos e de aprendizado e crescimento (REZENDE, 2003; COSTA, 2006).

$\mathrm{Na}$ perspectiva financeira são descritos os resultados tangíveis da estratégia em termos financeiros tradicionais, permitindo a identificação de quais indicadores devem ser considerados para avaliar o desempenho a longo prazo, além das variáveis mais importantes para criar e impulsionar os objetivos. Por meio da perspectiva clientes, os gestores podem dimensionar se as atividades da empresa estão alinhadas às estratégias para atender as necessidades e expectativas dos segmentos e mercados que querem atingir (ZAGO, 2006).

Na perspectiva processos internos, as empresas buscam a melhoria da qualidade dos produtos e serviços, a redução dos custos, o aumento da produção e a maximização da produtividade. A última perspectiva do BSC, aprendizado e crescimento, busca o desenvolvimento dos objetivos e medidas de desempenho para orientar o aprendizado e crescimento da organização.

Saber aonde se quer chegar e quais são as prioridades são pontos, portanto, 
fundamentais na construção do painel estratégico do BSC, que deve representar o pensamento e as energias da equipe que o elabora. Caso contrário, sem o engajamento de todos os envolvidos, o resultado mais provável é o fracasso (KAPLAN; NORTON, 2000).

Por painel estratégico tem-se a representação estruturada das estratégias de uma organização sob dos processos táticos e operacionais. Esta representação permite o acompanhamento e monitoração das ações táticas, como campanhas de marketing, e ações operacionais, como controle de qualidade e desequilíbrios orçamentários ocorridos em um pequeno espaço de tempo. A elaboração do painel estratégico bem estruturado permite, aos gestores, que a tomada de decisão seja mais rápida e a redução do trabalho administrativo em análise e pesquisa (PERSON, 2010).

Pelos Mapas Estratégicos do BSC têm-se a tradução da estratégia em objetivos, metas, indicadores, medidas e iniciativas que proporcionam o alinhamento dos esforços de todos os colaboradores à estratégia organizacional. Sua criação teve como base a constatação de que não se pode mensurar o que não se consegue descrever (SILVA NETO; MELO; PEREIRA, 2006).

O entendimento sobre os componentes supracitados é requisito básico para a implantação da ferramenta em qualquer ente, seja privado ou público, pois são nesses elementos que residem os caminhos para o cumprimento da razão social da organização.

Como barreiras para implementação do BSC, Chan (2004), que aplicou uma pesquisa junto aos governos municipais dos Estados Unidos e Canadá, constatou que o uso do BSC entre eles ainda é limitado, e identificou os seguintes fatores para tanto: falta de um sistema de informação adequado para dar suporte ao BSC, financiamento inadequado, e falta de comprometimento da alta administração, pelo tempo restrito dos gestores, muito ocupados com problemas de curto prazo.

Importante salientar que, embora o modelo BSC deva ser único, para a estratégia de cada empresa, evidências demonstram que elas tendem a confiar em medidas genéricas, principalmente em medidas de resultado (BRYANT et al., 2004). Assim, no que diz respeito à operacionalização e às medidas das quatro perspectivas do BSC, esta pesquisa utilizou as medidas amplamente apresentadas na literatura existente. 


\subsection{PESQUISAS SIMILARES}

A partir da consulta às bases de dados da CAPES, dos Anais do Simpósio de Excelência e Gestão (SEGeT) e do Encontro Nacional de Engenharia de Produção (ENENGEP) dos últimos 10 anos, elaborou-se o quadro 1 com as principais pesquisas sobre essa temática, a partir da percepção dos autores, apresentando o ano, os pesquisadores, o objetivo, os resultados e os instrumentos propostos - ferramentas para adaptação do Balanced Scorecard em organizações sem fins econômicos.

Quadro 01 - Pesquisas Similares

\begin{tabular}{|c|c|c|c|c|}
\hline Ano & Autor & Objetivo & Resultado & Instrumentos Proposto \\
\hline 2013 & $\begin{array}{l}\text { Machado, } \\
\text { Freitas, } \\
\text { Machado e } \\
\text { Freitas }\end{array}$ & $\begin{array}{l}\text { Propor um modelo de } \\
\text { gestão a uma } \\
\text { organização sem fins } \\
\text { lucrativos que } \\
\text { contemple a } \\
\text { mensuração do } \\
\text { desempenho } \\
\text { fundamentada no } \\
\text { Balanced Scorecard, } \\
\text { buscando contribuir } \\
\text { para a melhoria do seu } \\
\text { processo de gestão. }\end{array}$ & $\begin{array}{l}\text { Constatou-se a } \\
\text { viabilidade de } \\
\text { aplicação do BSC em } \\
\text { organizações não } \\
\text { governamentais. } \\
\text { Percebeu-se que a } \\
\text { ferramenta } \\
\text { possibilita que as } \\
\text { entidades sem fins } \\
\text { lucrativos se } \\
\text { tornassem mais } \\
\text { ativas e que seu } \\
\text { processo de gestão } \\
\text { seja orientado por } \\
\text { sua missão e visão, e } \\
\text { não pelo orçamento. }\end{array}$ & $\begin{array}{l}\text { Implantação do BSC foi } \\
\text { divida em sete etapas - } \\
\text { Definição dos limites da } \\
\text { Entidade; Definição da } \\
\text { Missão e a Visão; Definição } \\
\text { da Estratégia; Definição dos } \\
\text { Objetivos Estratégicos; } \\
\text { Escolha dos Indicadores; } \\
\text { Estabelecer Metas; Análise } \\
\text { dos Indicadores. O Painel } \\
\text { Estratégico e Mapa } \\
\text { Estratégico foram } \\
\text { apresentados na quinta } \\
\text { etapa. }\end{array}$ \\
\hline 2012 & $\begin{array}{l}\text { Lufit Jr., } \\
\text { Queiroz, } \\
\text { Hekis, } \\
\text { Lima e } \\
\text { Futukava }\end{array}$ & $\begin{array}{l}\text { Definir variáveis de } \\
\text { controle, metas e } \\
\text { interpretações para que } \\
\text { a organização estudada } \\
\text { apresente desempenho } \\
\text { positivo e crescimento } \\
\text { ao longo do tempo. } \\
\text { Utilizou-se como estudo }\end{array}$ & $\begin{array}{l}\text { Relativo } \\
\text { balanceamento e } \\
\text { alinhamento dos } \\
\text { objetivos } \\
\text { estratégicos, baixa } \\
\text { relação de } \\
\text { causalidade do } \\
\text { mapa, comunicação }\end{array}$ & $\begin{array}{l}\text { Painel Estratégico - } \\
\text { Perspectivas Financeira, } \\
\text { Sociedade, Aprendizado e } \\
\text { Crescimento e Processos } \\
\text { Internos, com } 15 \\
\text { indicadores estratégicos; } \\
\text { Mapa Estratégico e relações }\end{array}$ \\
\hline
\end{tabular}




\begin{tabular}{|c|c|c|c|c|}
\hline & & de caso a AACC/RN. & $\begin{array}{l}\text { estratégica } \\
\text { insuficiente e } \\
\text { fragmentada. }\end{array}$ & causa-efeito. \\
\hline 2010 & $\begin{array}{l}\text { Lebarcky, } \\
\text { Fernandes, } \\
\text { Mendes e } \\
\text { Silveira }\end{array}$ & $\begin{array}{l}\text { Investigar a viabilidade } \\
\text { de utilização do sistema } \\
\text { de medição de } \\
\text { desempenho Balanced } \\
\text { Scorecard (BSC) em } \\
\text { organizações do Terceiro } \\
\text { Setor, através da } \\
\text { proposição do modelo a } \\
\text { uma organização não } \\
\text { governamental. }\end{array}$ & $\begin{array}{l}\text { O BSC foi } \\
\text { considerado aplicável } \\
\text { em entidades do } \\
\text { Terceiro Setor, desde } \\
\text { que observadas as } \\
\text { particularidades e as } \\
\text { necessidades de } \\
\text { adaptação do } \\
\text { instrumento a essas } \\
\text { organizações. } \\
\text { A metodologia } \\
\text { revelou-se como uma } \\
\text { ferramenta de gestão } \\
\text { vantajosa para as } \\
\text { organizações sem } \\
\text { fins lucrativos por } \\
\text { facilitar a tradução e } \\
\text { a operacionalização } \\
\text { da estratégia } \\
\text { organizacional em } \\
\text { objetivos, metas e } \\
\text { ações. }\end{array}$ & $\begin{array}{l}\text { Criação de } 15 \text { indicadores } \\
\text { estratégicos das quatro } \\
\text { perspectivas e do Mapa } \\
\text { Estratégico do Centro de } \\
\text { Tecnologias Alternativas da } \\
\text { Zona da Mata, uma } \\
\text { organização não } \\
\text { governamental, cujas ações } \\
\text { se desenvolvem no sentido } \\
\text { de ampliar o conhecimento } \\
\text { e a prática da agroecologia, } \\
\text { bem como fortalecer a } \\
\text { agricultura familiar. }\end{array}$ \\
\hline 2009 & $\begin{array}{l}\text { Quintairos, } \\
\text { Costa, } \\
\text { Silva e } \\
\text { Oliveira }\end{array}$ & $\begin{array}{l}\text { Apresentar um modelo } \\
\text { de gestão estratégica } \\
\text { baseado no Balanced } \\
\text { Scorecard para uma } \\
\text { organização do Terceiro } \\
\text { Setor. }\end{array}$ & $\begin{array}{l}\text { O BSC permitiu a } \\
\text { integração da missão } \\
\text { e visão da } \\
\text { organização } \\
\text { estudada, de forma a } \\
\text { traduzi-la em } \\
\text { objetivos e medidas } \\
\text { que possibilitam a } \\
\text { avaliação do seu } \\
\text { desempenho sob o } \\
\text { ponto de vista de }\end{array}$ & $\begin{array}{l}\text { Estruturação do BSC na } \\
\text { Zambô, organização não- } \\
\text { governamental que defende } \\
\text { os interesses dos negros e } \\
\text { realizar ações para divulgar } \\
\text { e preservar a cultura afro- } \\
\text { brasileira, em quatro } \\
\text { perspectivas hierarquizadas } \\
\text { - Clientes, Capacitação e } \\
\text { Otimização de Recursos, } \\
\text { Processos Internos e }\end{array}$ \\
\hline
\end{tabular}

Revista Eletrônica de Estratégia \& Negócios, Florianópolis, v.9, n.1, jan./abr. 2016. 


\begin{tabular}{|c|c|c|c|c|}
\hline & & & $\begin{array}{l}\text { quatro perspectivas: } \\
\text { financeira, clientes, } \\
\text { processos internos e } \\
\text { aprendizado e } \\
\text { crescimento. }\end{array}$ & $\begin{array}{l}\text { Aprendizado e Crescimento, } \\
\text { bem como do } \\
\text { desenvolvimento de } 26 \\
\text { indicadores alinhados com a } \\
\text { missão e visão da entidade. }\end{array}$ \\
\hline 2007 & $\begin{array}{l}\text { Rocha, } \\
\text { Hang e } \\
\text { Furtado }\end{array}$ & $\begin{array}{l}\text { Analisar o Balanced } \\
\text { Scorecard como } \\
\text { ferramenta de gestão } \\
\text { estratégica na ONG } \\
\text { RIOVOLUNTÁRIO. }\end{array}$ & $\begin{array}{l}\text { Falta de refinamento } \\
\text { dos indicadores } \\
\text { estratégicos, das } \\
\text { metas e dos planos } \\
\text { de ação propostos no } \\
\text { BSC inicial (2005); } \\
\text { A partir da análise } \\
\text { dos indicadores } \\
\text { estratégicos e da } \\
\text { percepção dos } \\
\text { colaboradores da } \\
\text { organização, foram } \\
\text { aportadas } \\
\text { oportunidades de } \\
\text { melhoria para o } \\
\text { modelo anterior e } \\
\text { criação do novo. }\end{array}$ & $\begin{array}{l}\text { Painel Estratégico - } \\
\text { Perspectivas Financeira, } \\
\text { Partes Interessadas e } \\
\text { Processos Internos (Pessoas } \\
\text { e Cultura da Inovação), com } \\
11 \text { indicadores estratégicos; } \\
\text { Detalhamento dos } \\
\text { indicadores estratégicos; } \\
\text { Mapa Estratégico do } \\
\text { RIOVOLUNTÁRIO }\end{array}$ \\
\hline 2006 & $\begin{array}{l}\text { De Ré, } \\
\text { Limberger, } \\
\text { Petri e } \\
\text { Vianna }\end{array}$ & $\begin{array}{l}\text { Propor a utilização do } \\
\text { Balanced Scorecard } \\
\text { adaptado às } \\
\text { peculiaridades da RSAS - } \\
\text { Rede Salesiana de Ação } \\
\text { Social, por meio da } \\
\text { dimensão do } \\
\text { aprendizado } \\
\text { organizacional; Destacar } \\
\text { a importância da } \\
\text { implantação de um } \\
\text { sistema integrado que }\end{array}$ & $\begin{array}{l}\text { O BSC permitiu } \\
\text { apontar lacunas no } \\
\text { POI - Planejamento } \\
\text { Orgânico Inspetorial, } \\
\text { subsidiar a } \\
\text { elaboração de novas } \\
\text { estratégias e integrar } \\
\text { as ações da } \\
\text { organização. }\end{array}$ & $\begin{array}{l}\text { Elaboração de novas } \\
\text { Estratégias; Painel } \\
\text { Estratégico - Perspectivas } \\
\text { Financeira, Sociedade, } \\
\text { Aprendizado e Crescimento } \\
\text { e Processos Internos - } 11 \\
\text { indicadores estratégicos; } \\
\text { Mapa Estratégico e relações } \\
\text { causa-efeito. }\end{array}$ \\
\hline
\end{tabular}




\begin{tabular}{|l|l|l|l|}
\hline & $\begin{array}{l}\text { priorize o envolvimento } \\
\text { dos stakeholders. }\end{array}$ & & \\
\hline
\end{tabular}

Fonte: Dados da Pesquisa, 2014.

Apresentados os estudos anteriores, passa-se ao detalhamento acerca dos procedimentos metodológicos adotados por esta pesquisa.

\section{METODOLOGIA}

Esta seção tem por objetivo apresentar o enquadramento metodológico e os procedimentos de coleta e análise dos dados.

\subsection{ENQUADRAMENTO METODOLÓGICO}

Quanto aos seus objetivos, a metodologia utilizada foi descritiva e exploratória, uma vez que, além de observa fatos, registra-los, analisa-los, classifica-los e interpreta-los sem que o pesquisador interfira ou manipule os dados coletados, busca a geração de conhecimento nos pesquisadores e nos gestores da entidade (ANDRADE, 2002; RICHARDSON, 2008).

Considerando o problema de pesquisa, os métodos podem ser divididos em qualitativo, quantitativo e qualitativo/quantitativo. A abordagem deste estudo enquadra-se como qualitativa, sob a forma de um estudo de caso. A justificativa para tal opção reside no fato da necessidade de aferir efetividade no modelo de avaliação de desempenho e de gestão que será construído para a entidade (PETRI, 2005; RICHARDSON, 2008).

Quanto aos procedimentos de pesquisa, as proposições acadêmicas podem ser de dois tipos: bibliográficas e documentais. De acordo com Gil (1999), as pesquisas bibliográficas são desenvolvidas por meio de material já elaborado - livros e artigos científicos. Em se tratando de material que ainda não tenha recebido o devido tratamento análise analítica, a pesquisa é classificada, segundo o mesmo autor, como pesquisa documental.

Sobre a estratégia de pesquisa, que define como a pesquisa será conduzida, Triviños (1992) classifica-a em pesquisa básica e a aplicada. Na pesquisa básica, os resultados obtidos 
são generalizações e apresentam como característica principal a repetitividade, quando da utilização do mesmo procedimento (PETRI, 2005). A pesquisa aplicada, por sua vez, caracteriza-se pelo fato dos resultados obtidos serem personalizados ao contexto que foi estudado. Neste caso não há repetitividade de resultados, caso o mesmo procedimento seja aplicado em outro contexto. O que pode ser reaplicado é o processo de pesquisa.

A partir deste conceito, utilizou-se como estratégia de pesquisa aplicada, uma vez que se objetiva construir um modelo de avaliação de desempenho, baseados no BSC, personalizado e participativo para os tomadores de decisão da organização estudada.

Em relação à lógica, a pesquisa pode ser dedutiva ou indutiva. Segundo Creswell (2010), os estudos indutivos são utilizados quando se busca o conhecimento de um problema ainda inexplorado, trazendo novos esclarecimentos para o meio científico. Com base neste conceito, este artigo classifica-se como de lógica indutiva, pois o conhecimento gerado no processo baseia-se na visão particular dos pesquisadores e dos gestores, por meio das delimitações por estes últimos estabelecidas.

\subsection{PROCEDIMENTOS DE COLETA E ANÁLISE DOS DADOS}

Quanto aos instrumentos utilizados na coleta de dados como sustentação ao embasamento teórico, e as conclusões e recomendações da pesquisa foram: entrevista semiestruturada com o corpo diretivo da unidade organizacional de Santa Catarina; a observação, mediante visitas técnicas realizadas em 2013; e análise dos documentos.

É importante salientar que, nesta etapa, foram utilizados dados primários e secundários. Os dados primários foram coletados a partir de entrevistas semiestruturadas com o diretor executivo da fundação educacional e sua equipe administrativa. O objetivo destas entrevistas foi identificar os elementos mais relevantes para o gestor e que são utilizados para a tomada de decisão. A partir desta identificação, os pesquisadores discutiram com os entrevistados a fim de nivelar conhecimentos sobre como foi o processo de elaboração dos indicadores, ocorrido em 2008, bem como identificar os objetivos estratégicos e aspirações a serem utilizados em cada uma das perspectivas do Balaced Scorecard. 
Em seguida, foram coletados os dados secundários por meio de minuciosa pesquisa documental em relatórios gerenciais, documentos contábeis, relatório de ações e resultados dos cinco anos anteriores ao início da pesquisa, além do site da organização. Com esses dados, os pesquisadores iniciaram a etapa de análise de conteúdo, classificada por Bardin (1977) como conjunto de técnicas de análise que visa a obter indicadores que permitam inferências de conhecimentos relativos às condições de produção/recepção destas mensagens. Essa técnica foi utilizada no tratamento de dados, subsidiando a elaboração e a análise dos indicadores, que foram a base das metas traçadas.

\section{A ORGANIZAÇÃO}

Criada no início do século XX, a entidade é uma organização sem fins econômicos, de cunho educacional, que tem como objetivo despertar o espírito empreendedor em jovens, estimulando o desenvolvimento pessoal e facilitando o acesso ao mercado de trabalho.

Por meio de programas e projetos desenvolvidos em escolas e entidades educacionais, a organização oportuniza o conhecimento e a vivência de situações relacionadas à economia, cujas temáticas abarcam questões sobre sustentabilidade e ética. Fundada no final da década de 1990 em Santa Catarina, a organização promove a participação de empresários, voluntários, pais, professores e alunos, envolvendo, até 2012, mais de 250 mil estudantes.

A entidade é mantida e administrada por empresas e entidades privadas que investem recursos financeiros e humanos para aplicação das ações educacionais. Os programas são desenvolvidos de forma gratuita, em entidades, escolas públicas e particulares de 52 cidades catarinenses, dentre elas: Blumenau, Chapecó, Criciúma, Florianópolis, Joaçaba e Joinville.

A missão organizacional é Despertar o espírito empreendedor nos jovens, ainda na escola, e proporcionar uma visão clara do mundo dos negócios. No que tange à visão da entidade, tem-se: Consolidar a cultura empreendedora formando uma geração de lideranças nas áreas empresarial, educacional, social e política. Os valores da entidade são: Honestidade, Ética, Perseverança, Respeito, Coragem, Sensibilidade, Sustentabilidade. 
Com base nestes princípios, características e objetivos, bem como nos dados coletados descritos na seção 3, desenvolveram-se o Mapa Estratégico e os Painéis Estratégicos e de Indicadores da organização com base no BSC.

\subsection{O PROCESSO DE IMPLANTAÇÃO DO BSC}

A adaptação do Balanced Scorecard como ferramenta de avaliação de desempenho e de gestão, assim como seus autores preconizam, não seguiu um modelo padrão, sendo adaptado de acordo com as características e objetivos da entidade estudada.

A seguir, apresentam-se os elementos estratégicos construídos a partir dos resultados da pesquisa. Cabe ressaltar que, por meio de relações causa-efeito, entende-se que os objetivos estabelecidos na perspectiva financeira só serão alcançados a partir do atingimento dos objetivos da perspectiva clientes que, por sua vez, dependem do alcance dos objetivos da perspectiva processos internos. Da mesma forma, estes objetivos serão atingidos quando os objetivos da perspectiva aprendizado e crescimento forem atendidos.

Figura 02 - Mapa Estratégico da Organização

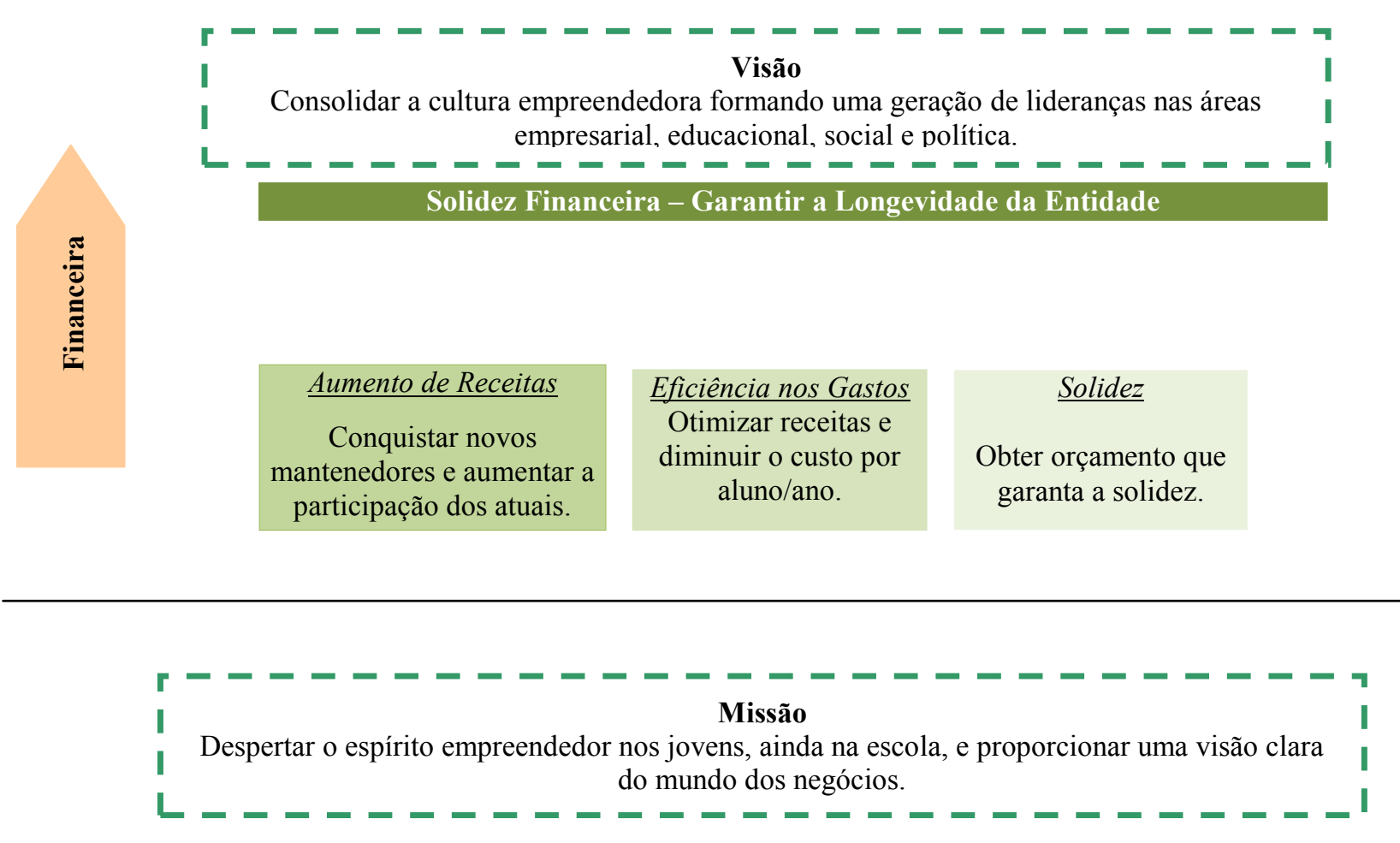

Revista Eletrônica de Estratégia \& Negócios, Florianópolis, v.9, n.1, jan./abr. 2016. 


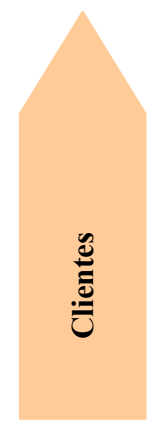

Mantenedores

Aumentar o envolvimento da iniciativa privada

Melhorar o relacionamento com mantenedores e entidades de classe.

\section{Voluntários}

\section{Participacão}

Aumentar o número de voluntários e o número de horas de atuação destes.

\section{Escolas}

\section{Expansão}

Aumentar o número de escolas, programas desenvolvidos e o número de alunos atendidos.

Equilibrar a proporção entre escolas públicas e privadas.

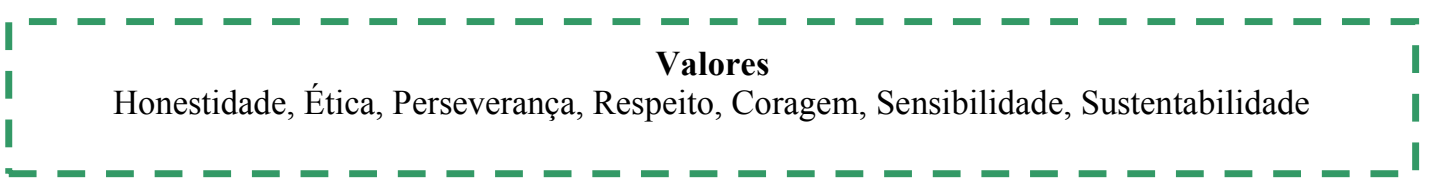

Melhoria Contínua

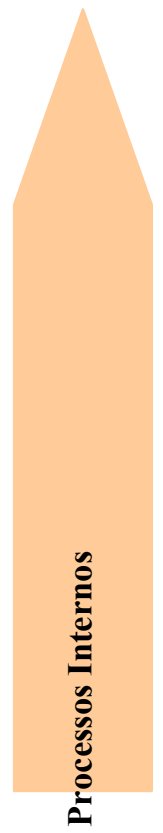

Captação de recursos

Aumentar a eficiência na captação de recursos

\begin{tabular}{|c|}
\hline $\begin{array}{l}\text { Logística de materiais } \\
\text { Aumentar a eficiência dos processos } \\
\text { logísticos }\end{array}$ \\
\hline $\begin{array}{c}\text { Impacto das ações de comunicação } \\
\text { Aumentar a exposição positiva da } \\
\text { marca }\end{array}$ \\
Aumentar o índice de percepção \\
positiva dos alunos e o número de \\
programas desenvolvidos no Estado
\end{tabular}

Gestão das Informações e do Conhecimento

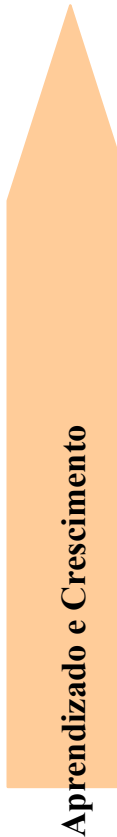

\section{Pessoas}

Diminuir do Turnover

Aumentar o número de horas de capacitação

\section{Comunicação}

Aumentar o grau de satisfação dos públicos com o bloco de comunicação 
Fonte: Elaborado pelos autores (2015).

Na construção do painel estratégico - quadros 2 a 5, a primeira coluna corresponde aos objetivos estratégicos de cada uma das perspectivas que, assim como os indicadores estratégicos, foram estabelecidos a partir da missão, visão e valores organizacionais. Na quarta coluna são apresentadas as metas para que os itens das colunas anteriores sejam cumpridos, em consonância com os componentes estratégicos supracitados. Na terceira e quarta colunas, apresentam-se a periodicidade de acompanhamento e da justificativa para o desenvolvimento dos objetivos e indicadores estratégicos.

As demais colunas apresentam os objetivos estratégicos de cada uma das perspectivas, assim como a descrição do mesmo e o indicador de desempenho obtido no final de 2012.

Cabe salientar que os indicadores que aparecem sem valor (zerados) foram criados pela organização, mas não foram disponibilizados até o final da presente pesquisa ou medidos por interesse do gestor. 
Quadro 02 - Perspectiva Financeira

\begin{tabular}{|c|c|c|c|c|c|c|}
\hline Objetivo & Indicadores & Controle & Justificativa/observações & Meta & ID Anterior & ID Atual \\
\hline \multirow[t]{4}{*}{ Aumento de } & $\begin{array}{l}\text { Receita Bruta ano corrente/ano } \\
\text { anterior }\end{array}$ & Anual & \multirow{4}{*}{$\begin{array}{l}\text { O aumento de receitas deve levar em } \\
\text { consideração a conquista de novos } \\
\text { parceiros e o aumento do envolvimento } \\
\text { dos atuais conselheiros. }\end{array}$} & $18 \%$ & $2.7 \%$ & 1,137495079 \\
\hline & $\begin{array}{l}\% \text { aumento da receita proveniente } \\
\text { de novos parceiros }\end{array}$ & Anual & & $10 \%$ & $2.7 \%$ & 0,135036834 \\
\hline & $\begin{array}{l}\% \text { aumento da receita proveniente } \\
\text { de parceiros antigos }\end{array}$ & Anual & & $3 \%$ & $0 \%$ & 0,850077339 \\
\hline & $\begin{array}{l}\text { \% aumento da receita proveniente } \\
\text { de projetos e eventos especiais }\end{array}$ & Anual & & $5 \%$ & $0 \%$ & 0,014885827 \\
\hline \multirow[t]{3}{*}{ Eficiência nos } & $\begin{array}{l}\text { I - Alunos atendidos ano corrente / } \\
\text { receita ano corrente }\end{array}$ & Anual & \multirow{3}{*}{$\begin{array}{l}\text { A eficiência nos gastos leva em } \\
\text { consideração a quantidade de alunos } \\
\text { beneficiados em relação à receita, além } \\
\text { de avaliar a evolução desse indicador em } \\
\text { relação ao ano anterior. }\end{array}$} & $0.06 \%$ & $0.06 \%$ & 0,048772234 \\
\hline & $\begin{array}{l}\text { II - Alunos atendidos ano anterior / } \\
\text { receita ano anterior }\end{array}$ & Anual & & $0.05 \%$ & $0.05 \%$ & 0,060670554 \\
\hline & Índice I / Índice II & Anual & & $1.2 \%$ & $1.2 \%$ & 0,80388642 \\
\hline Solidez & $\%$ reserva sobre a receita & Anual & Certo nível de poupança é considerado & $12 \%$ & $14.75 \%$ & 0 \\
\hline
\end{tabular}

Revista Eletrônica de Estratégia \& Negócios, Florianópolis, v.9, n.1, jan./abr. 2016. 
O BALANCED SCORECARD EM ORGANIZAÇÕES SEM FINS ECONÔMICOS: UM ESTUDO DE CASO

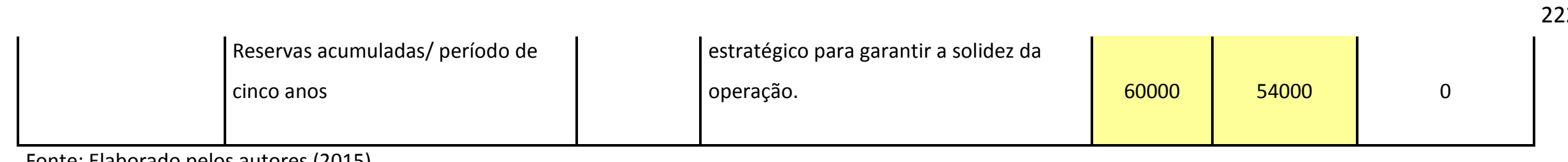

Fonte: Elaborado pelos autores (2015).

Quadro 03 - Perspectiva de clientes

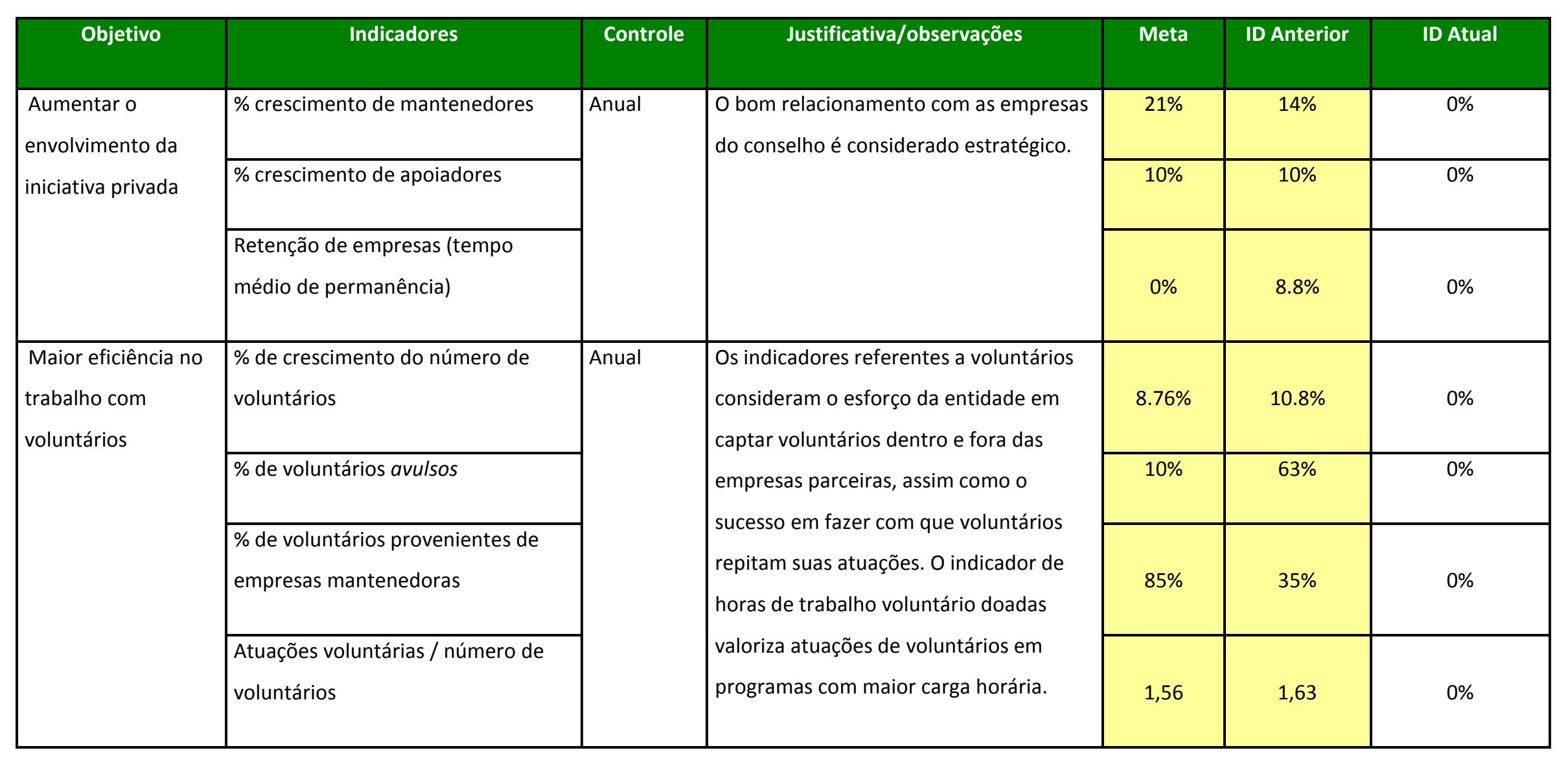

Revista Eletrônica de Estratégia \& Negócios, Florianópolis, v.9, n.1, jan./abr. 2016. 
O BALANCED SCORECARD EM ORGANIZAÇÕES SEM FINS ECONÔMICOS: UM ESTUDO DE CASO

Marcelo Medeiros da Rosa - Sérgio Murilo Petri - Patrícia Bianco - Ibsem Agrello Dias

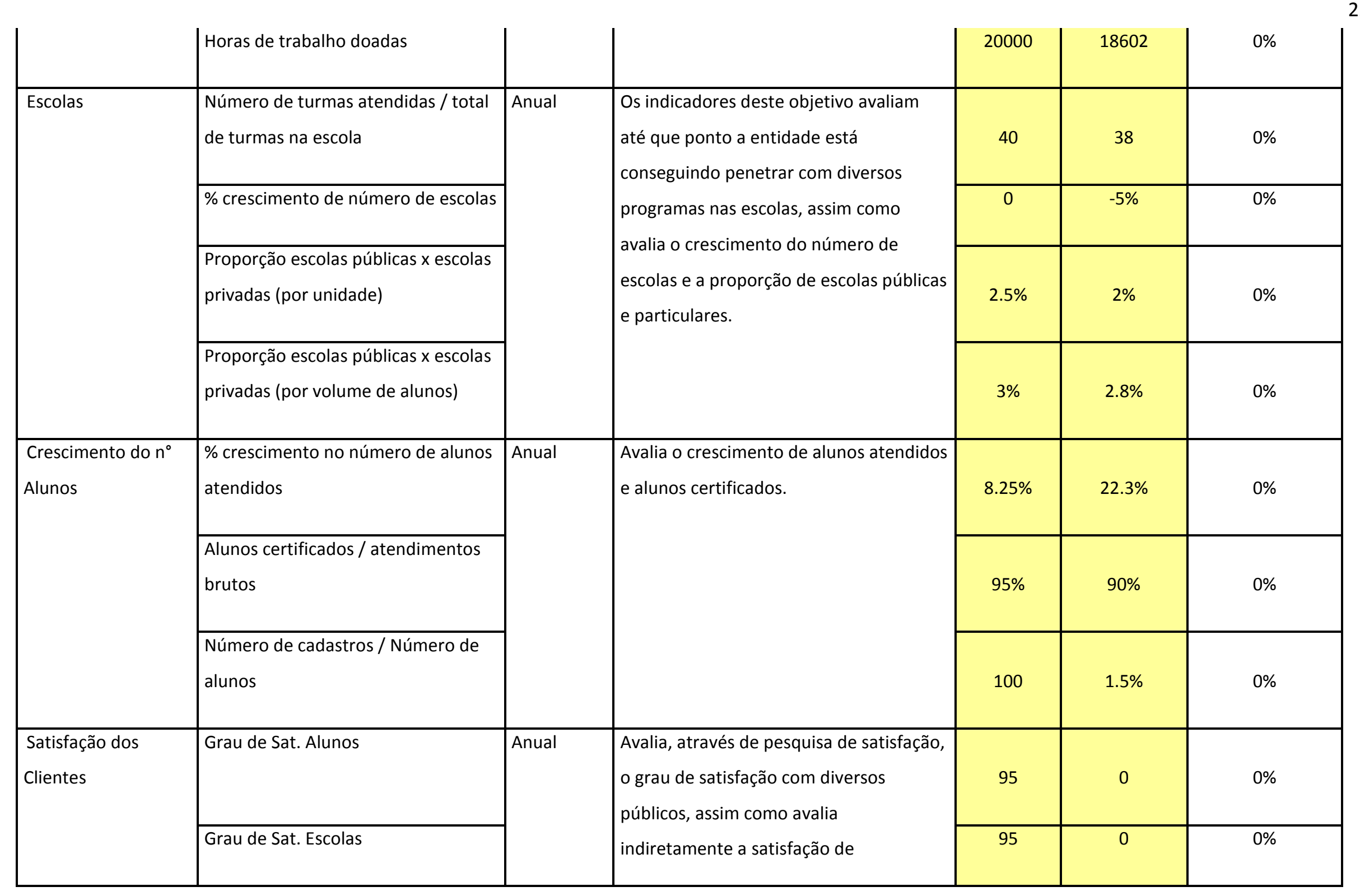

Revista Eletrônica de Estratégia \& Negócios, Florianópolis, v.9, n.1, jan./abr. 2016. 
O BALANCED SCORECARD EM ORGANIZAÇÕES SEM FINS ECONÔMICOS: UM ESTUDO DE CASO

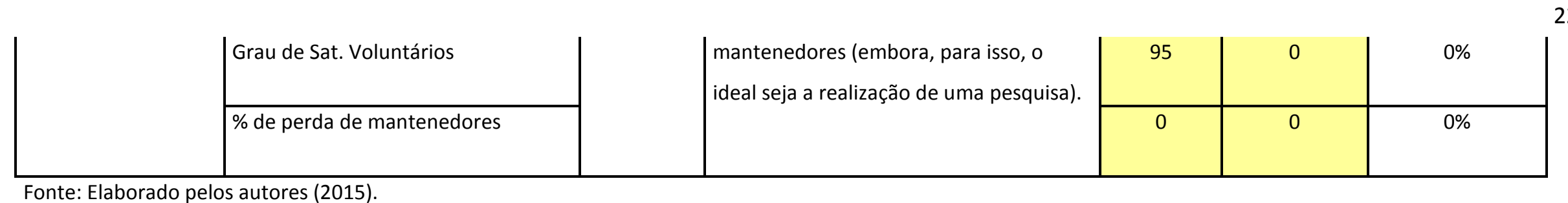

Fonte: Elaborado pelos autores (2015).

\section{Quadro 04 - Processos Internos da Empresa}

\begin{tabular}{|c|c|c|c|c|c|c|}
\hline Objetivo & Indicadores & Controle & Justificativa/observações & Meta & ID Anterior & ID Atual \\
\hline \multirow{5}{*}{$\begin{array}{l}\text { Aumentar o impacto } \\
\text { das ações de } \\
\text { comunicação }\end{array}$} & \% crescimento de inserções na mídia & \multirow[t]{5}{*}{ Anual } & \multirow{5}{*}{$\begin{array}{l}\text { Embora fortemente baseado em } \\
\text { indicadores quantitativos, o objetivo de } \\
\text { aumento do impacto das ações de } \\
\text { comunicação avalia a exposição da marca } \\
\text { ao maior número de pessoas. }\end{array}$} & $10 \%$ & $5 \%$ & 0 \\
\hline & $\begin{array}{l}\text { \% crescimento de minutagem total } \\
\text { do clipping da entidade }\end{array}$ & & & $10 \%$ & $5 \%$ & 0 \\
\hline & $\begin{array}{l}\text { \% crescimento de centimetragem } \\
\text { total do clipping da entidade }\end{array}$ & & & $10 \%$ & $5 \%$ & 0 \\
\hline & $\begin{array}{l}\text { Estimativa de pessoas participantes } \\
\text { dos eventos (formaturas, feiras, etc.) }\end{array}$ & & & 14000 & 12000 & 0 \\
\hline & Visitantes no site & & & & & 0 \\
\hline \multirow{2}{*}{$\begin{array}{l}\text { Logística de } \\
\text { materiais }\end{array}$} & Registro de atrasos & \multirow[t]{2}{*}{ Anual } & \multirow{2}{*}{$\begin{array}{l}\text { Controles sobre os problemas com a } \\
\text { logística. }\end{array}$} & 0 & 0 & 0 \\
\hline & Índice de desperdício & & & 0 & 1 & 0 \\
\hline
\end{tabular}

Revista Eletrônica de Estratégia \& Negócios, Florianópolis, v.9, n.1, jan./abr. 2016. 
O BALANCED SCORECARD EM ORGANIZAÇÕES SEM FINS ECONÔMICOS: UM ESTUDO DE CASO

Marcelo Medeiros da Rosa - Sérgio Murilo Petri - Patrícia Bianco - Ibsem Agrello Dias

\begin{tabular}{|c|c|c|c|c|c|c|}
\hline \multirow[t]{2}{*}{$\begin{array}{l}\text { Captação de } \\
\text { recursos }\end{array}$} & $\begin{array}{l}\text { Visitas de prospecção de } \\
\text { mantenedores / pessoa envolvida na } \\
\text { prospecção }\end{array}$ & \multirow[t]{2}{*}{ Anual } & \multirow[t]{2}{*}{$\begin{array}{l}\text { Medidas de eficiência na captação de } \\
\text { recursos. }\end{array}$} & 50 & 40 & 0 \\
\hline & $\begin{array}{l}\text { Voluntários sensibilizados / total de } \\
\text { voluntários }\end{array}$ & & & 1,5 & 1 & 0 \\
\hline \multirow[t]{4}{*}{$\begin{array}{l}\text { Objetivos de } \\
\text { aprendizagem }\end{array}$} & $\begin{array}{l}\text { Grau de concordância dos alunos } \\
\text { com os objetivos da entidade } \\
\text { (pesquisa) }\end{array}$ & \multirow[t]{4}{*}{ Anual } & \multirow{4}{*}{$\begin{array}{l}\text { Este objetivo é medido através de } \\
\text { indicadores de percepção dos alunos, } \\
\text { participação do programa " } X \text { " sobre o } \\
\text { total de alunos, acompanhamento de } \\
\text { programas nas escolas e } \\
\text { complementação da grade de programas } \\
\text { no estado. }\end{array}$} & & & 0 \\
\hline & $\begin{array}{l}\text { Alunos do programa " } \mathrm{X} \text { " / total de } \\
\text { alunos }\end{array}$ & & & 3,5 & 3,7 & 0 \\
\hline & $\begin{array}{l}\text { Visitas de acompanhamento / } \\
\text { turmas e por voluntários }\end{array}$ & & & 2,5 & 2,5 & 0 \\
\hline & $\begin{array}{l}\text { Percentual da grade de programas } \\
\text { operando no Estado }\end{array}$ & & & 1,7 & 1,7 & 0 \\
\hline
\end{tabular}

Fonte: Elaborado pelos autores (2015).

Quadro 05 - Perspectiva de Aprendizado e Crescimento

Revista Eletrônica de Estratégia \& Negócios, Florianópolis, v.9, n.1, jan./abr. 2016. 
O BALANCED SCORECARD EM ORGANIZAÇÕES SEM FINS ECONÔMICOS: UM ESTUDO DE CASO

\begin{tabular}{|c|c|c|c|c|c|c|}
\hline Objetivo & Indicadores & Controle & Justificativa/observações & Meta & ID Anterior & ID Atual \\
\hline \multirow[t]{3}{*}{$\begin{array}{l}\text { Boa gestão de } \\
\text { pessoas }\end{array}$} & Rotatividade da equipe & \multirow[t]{3}{*}{ Anual } & \multirow{3}{*}{$\begin{array}{l}\text { Este objetivo leva em consideração os } \\
\text { esforços de capacitação da equipe, assim } \\
\text { como a rotatividade da mesma. }\end{array}$} & 0 & 0,6 & 0 \\
\hline & $\begin{array}{l}\text { Horas de treinamento (interno e } \\
\text { externo) / colaborador }\end{array}$ & & & 100 & 30 & 0 \\
\hline & $\begin{array}{l}\text { Média de horas de sala de aula por } \\
\text { colaborador }\end{array}$ & & & 60 & 120 & 0 \\
\hline Comunicação & $\begin{array}{l}\text { Grau de satisfação dos públicos com } \\
\text { o bloco de comunicação }\end{array}$ & Anual & $\begin{array}{l}\text { Este indicador é composto de uma série } \\
\text { de dimensões na pesquisa de satisfação. }\end{array}$ & & & 0 \\
\hline
\end{tabular}

Fonte: Elaborado pelos autores (2015).

Revista Eletrônica de Estratégia \& Negócios, Florianópolis, v.9, n.1, jan./abr. 2016. 
Ao analisar o Mapa e o Painel Estratégicos da entidade, o leitor pode perceber que as quatro perspectivas e as quatro aspirações (Financeira - Solidez Financeira; Clientes Satisfação; Processos Internos - Melhoria Contínua; e Aprendizado e Crescimento - Gestão das Informações e do Conhecimento), assim como o modelo proposto por Kaplan e Norton, relacionam-se entre si e com a missão, visão e valores organizacionais por meio do estabelecimento de relações de causa e efeito entre os doze objetivos estratégicos apresentados.

Para ilustrar este entendimento, deduz-se que uma prática de gestão que aumente o indicador média de horas de sala de aula por colaborador, ligado ao objetivo estratégico boa gestão de pessoas da Perspectiva Aprendizado e Crescimento terá reflexo positivo nos indicadores visitas de acompanhamento de turmas/voluntários da Perspectiva Processos Internos e grau de satisfação dos voluntários da Perspectiva Clientes, contribuindo com a aspiração satisfação - aumentar o grau de satisfação dos diversos públicos. Ao compreender as relações de causalidade, a organização obtém um retrato dos impactos de suas ações para o atingimento da missão pré-estabelecida.

Em relação aos indicadores e seu desempenho de forma global, com base no Painel Estratégico, nota-se que ainda não há condições de se aferir o estágio atual da organização, dada a não publicação/disponibilização dos dados, seja por falta de um sistema de informação ou outros fatores internos. Este fato compromete também a possibilidade dos gestores elaborarem ações corretivas alinhadas à missão e visão da entidade.

Apesar desta situação, o Painel Estratégico tende a melhorar a compreensão dos diversos stakeholders (mantenedores, voluntários, força de trabalho, instituições de ensino, sociedade, etc.) sobre as estratégias da organização e melhorar a imagem institucional.

Com a interação entre as quatro perspectivas do BSC por meio do mapa e dos painéis apresentados, têm-se a criação de valor sustentável para a sociedade por meio dos ativos intangíveis da organização, da eficiência na gestão financeira e no cumprimento de sua missão e visão de futuro.

Vê-se, portanto, que o BSC permite a adequação das diretrizes estratégicas e gerenciais na aplicação correta dos recursos em processos operacionais da entidade, 
contribuindo sensivelmente para a melhoria na imagem institucional da entidade e de seus mantenedores.

\section{CONCLUSÕES}

Por explicar as relações entre o planejamento estratégico e operacional, o BSC diferencia-se das demais ferramentas gerenciais equilibrando, por meio das perspectivas do scorecard, os objetivos de longo e curto prazo, os resultados almejados e os vetores do desempenho destes resultados. Porém, como os próprios autores deste método indicam, não existe fórmula única para a aplicação de suas perspectivas. É necessário que o BSC seja adaptado às características de cada organização, permitindo que granularidades existentes no negócio sejam analisadas e discutidas no desenvolvimento do modelo.

Este artigo cumpriu seu objetivo ao evidenciar, com base no estudo de caso da entidade pesquisada, a aplicabilidade do Balanced Scorecard em organizações sem fins econômicos. Como observado no decorrer das seções, as interações causa-efeito demonstradas por meio dos painéis e do mapa estratégico da organização estudada mostram-se úteis na tradução da estratégia em metas mensuráveis e a ligação lógica entre os objetivos, os indicadores de desempenho e os resultados esperados, facilitando a compreensão, o controle e a execução das metas traçadas pela entidade, cujo nome institucional e dos seus programas e projetos foram suprimidos por solicitação dos seus gestores.

Ademais, espera-se que os instrumentos desenvolvidos sirvam como base para o acompanhamento dos indicadores, e permitam que os objetivos estratégicos possam ser revistos antes mesmo do final do ciclo. Este processo permitirá a verificação e correção de desvios estratégicos, operacionais e na alocação de recursos da entidade. Como consequência, ao alinhar as diretrizes estratégicas e os processos táticos/operacionais, o BSC tende a permitir a melhoria na gestão global e da imagem das organizações que fazem parte do conselho (mantenedores), demonstrando sua capacidade técnica na disseminação da cultura empreendedora no Estado de Santa Catarina.

Vale destacar, também, que o modelo elaborado é personalizado, não sendo possível generalizá-lo. Outra limitação é a existência de indicadores não mensurados no 
último ciclo avaliado por falta de interesse do diretor executivo e dos gerentes táticos, impedido que fossem feitas análises e inferências sobre estes.

Com base nessas limitações pode-se recomendar, para futuras pesquisas, o refinamento do mapa, dos painéis estratégicos e da base teórica sobre avaliação de desempenho, por meio da inclusão da teoria da mensuração tratada em Petri (2005). Desta forma, será possível evidenciar qual é a valoração da situação atual e comparar com os incrementos gerados com as metas estabelecidas, sendo possível, também, a análise de custos versus benefícios, ou seja, o quanto de incremento gerado dividido pelo custo de se fazer determinada iniciativa ou ação.

\section{REFERÊNCIAS}

ANDRADE, M. M. Introdução à metodologia do trabalho científico. São Paulo: Atlas, 2002.

ATKINSON, A. A; EPSTEIN, M. J. Measure for Measure - Realizing the Power of The Balanced Scorecard. CMA Management, 23 - 28, Canada. Set., 2000.

BARDIN, L. Análise de Conteúdo. Lisboa: Edições 70, 1977.

BIAZZO, S.; GARENGO, P. Performance measurement with the balanced scorecard: a practical approach to implementation within SMEs. Berlin: Springer, 2012.

BRYANT, L.; JONES, D. A.; WIDENER, S. K.. Managing value creation within the firm: An examination of multiple performance measures. Journal of Management Accounting Research, 16, 107-133, 2004.

CASTRO, C. M. A prática da pesquisa. São Paulo: McGraw-Hill, 1977.

CHAN, Yee-Ching Lilian. Performance measurement and adoption of balanced scorecards: A survey of municipal governments in the USA and Canadá. International Journal of Public Sector Management, v.17, n.3, p. 204 - 221, 2004.

COSTA, Ana Paula Paulino da. Balanced Scorecard: Conceitos e guia de implementação. 1a ed. São Paulo: Atlas, 2006.

CRESWELL, J. W. Projeto de pesquisa: métodos qualitativo, quantitativo e misto. 3.ed. Porto Alegre: Artmed/Bookman, 2010.

DIAS, Ibsem Agrello; DE LIMA, Maurício Andrade; DA ROSA, Marcelo Medeiros. Um referencial teórico: o desempenho financeiro de empresas que utilizam o balanced scorecard. Revista Eletrônica de Estratégia \& Negócios, v. 7, n. 3, p. 166-191, 2014.

EPSTEIN, M.J. The balanced scorecard and tableaux de board: translating strategy into action. Management Accounting, v. 79, n. 2, p. 28-37, 1997. 
GIL, Antônio Carlos. Métodos e Técnicas de Pesquisa Social. 5. Ed. São Paulo: Atlas, 1999.

KAPLAN, R. S.; NORTON, D. P. The balanced scorecard: measures that drive performance. Harvard Business Review, v. 70, n. 1, p. 71-80, jan./feb. 1992.

KAPLAN, Robert S.; NORTON, David P. A Estratégia em Ação: Balanced Scorecard. 24a Ed. Rio de Janeiro: Elsevier, 1997.

KAPLAN, Robert S.; NORTON, David P. Mapas Estratégicos: Convertendo ativos intangíveis em resultados tangíveis. Rio de Janeiro: Elsevier, 2004.

KAPLAN, Robert S.; NORTON, David P. Organização Orientada para a Estratégia: Como as empresas que adotaram o Balanced Scorecard prosperam no novo ambiente de negócios. Rio de Janeiro: Elsevier, 2000.

LEBARCKY, F. V. ; FERNANDES, A. R. ; MENDES, A. C. A. ; SILVEIRA, T. S. . O Balanced Scorecard como ferramenta de avaliação de desempenho organizacional no Terceiro Setor. In: VII Congresso USP de Controladoria e Contabilidade, 2010, São Paulo. VII Congresso IC USP Controladoria e Contabilidade, 2010.

LIMA, Carlos Rogério Montenegro de; SOARES, Thiago Coelho; DE LIMA, Mauricio Andrade. Balanced Scorecard em Instituições de Ensino Superior: uma análise das perspectivas. Revista Eletrônica de Estratégia \& Negócios, v. 4, n. 1, p. 183-205, 2011.

MACHADO, M. A. V.; FREITAS, M. M. M.; MACHADO, M. R.; FREITAS, W. O Balanced Scorecard em Entidades sem Fins Lucrativos: Um Estudo De Caso. Revista de Informação Contábil (UFPE), v. 7, p. 35-54, 2013.

MOREIRA, F. A. L; PESSOA, M. N. M; CABRAL, A. C. A; SANTOS, S. M; ROLDAN, V. P.S. Fatores Críticos na Implantação do Balanced Scorecard (BSC). Revista Estratégia \& Negócios. Florianópolis, v. 5, n. 3, p. 57-89, set/dez 2012.

NIVEN, Paul R. Balanced Scorecard Passo-a-Passo: Elevando o Desempenho e Mantendo Resultados. Rio de Janeiro: Ed. Qualitymark, 2007.

PERSON, Ron. Balanced Scorecard \& Painéis Estratégicos com o Microsoft ${ }^{\circledast}$ Excel $^{\circledast}$. Rio de Janeiro: Editora Alta Books, 2010.

PETRI, Sérgio Murilo. Modelo para apoiar a avaliação das abordagens de gestão de desempenho e sugerir aperfeiçoamentos: sob a ótica construtivista. Tese (doutorado) Engenharia da Produção. Universidade Federal de Santa Catarina, Florianópolis, 2005.

QUINTAIROS, P. ; COSTA, E.S. ; SILVA, M. A. V. R.; OLIVEIRA, E. A. A. Q. O. Aplicação do Balanced Scorecard a uma organização do Terceiro Setor. Revista de Desenvolvimento Econômico - RDE, v. 11, p. 75-81, 2009.

REZENDE, José Francisco. Balanced Scorecard e a gestão do Capital Intelectual: Alcançando a performance balanceada na economia do conhecimento. 6a ed. Rio de Janeiro: Elsevier, 2003. 
RICHARDSON, R.J. Pesquisa social: métodos e técnicas. 3. ed. São Paulo: Atlas, 1999.

SILVA NETO, J. M.; MELO, R. P.; PEREIRA, S. A. Resultados Notáveis na Administração Pública: Avaliação de Programas Utilizando Mapas Estratégicos e o Balanced Scorecard. In: Encontro Nacional da Associação Nacional dos Programas de Pós-Graduação e Pesquisa em Administração, 30; 2006, Salvador. Anais. Salvador: XXX ENANPAD, 2006.

TRIVIÑOS, Augusto N. S. Introdução à Pesquisa em Ciências Sociais. São Paulo: Atlas, 1992.

ZAGO, Sílvio Luís da Silva. Balanced Scorecard como ferramenta na gestão do orçamento público: caso prático DMAE - Porto Alegre. Dissertação de Mestrado Profissional em Economia: Universidade Federal do Rio Grande do Sul. Porto Alegre, 2006. 